\title{
LESSON 81
}

Open Punctuation

There may be a full stop after 'ref' if a sheet has a printed heading.

PAPER: A4.

MARGINS:

Left, Pica, 10; Elite, 12.

Set $a t a b$ in the middle of the sheet.

Type these framework examples and keep them for reference. Write or type in the instructions. The heading is 'Open Punctuation'.

Turn up 18 single lines for the body of the letter.

Letter 38

PAPER: A5.

MARGINS: Suitable.

TARGET TIME: 10 minutes.

Type this letter using open punctuation.

UNIT 21
To save time, the Civil Service and many firms prefer to use 'open punctuation' in their letters. This means leaving out all full stops and commas in the date, reference and inside address; the leaving out of the comma after the salutation and the complimentary close and the full stop after any enclosure. The letters 'st' ' $r d$ ' 'nd' or 'th' are left out of the date.

This method of typing is not yet accepted for envelopes.
Ref WK/MT

(Turn up 3 single lines)

10 November $19 .$.

(Turn up 3 single lines)

$R$ Hawkes Esq

52 Pendeford Avenue

Bristol NW3 6BR

(Turn up 3 single lines)

Dear Sir

(Turn up 2 single lines)

Thank you for your letter etc. Body of the letter is typed and punctuated as normal.

your order soon.

(Turn up 2 single lines)

Yours faithfully

$W$ KIRBY LTD

(Turn up 5 single lines)

Walter Kirby

Manager

(Turn up 2 single lines)

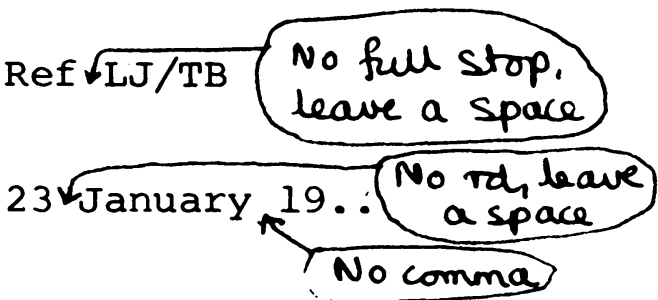

Black \& White Steel Co Ltd Warf Lane Sheffield $\mathrm{SHI}$ 9WL

No puncruation. leave a space batween words and abbreviations.

Dear sirs No comna

Thank you for your letter etc Punchuate the body of the later as usual. With your satisfaction. Sornal

Yours faithfully MESSRS JONES \& BRAMMER

Lesley Jones Accountant

Encs



Ref ST/DC As for despatch to-day

F Selby Ltd 16 stourbridge street Taunton s04 7TA

Dear Sirs

Will you please send us a list of all office Typewriters you have on offer. We are mainly interested in electric machines and would prefer a choice of type styles. We wish to replace our existing machines at the start of our financial year which begins next month. (Paragraph) Please enclose a copy of your Service Contract. Yours faithfully Susan Thomas Assistant Buyer

LESSON 81 